University of Nebraska - Lincoln

DigitalCommons@University of Nebraska - Lincoln

1986

\title{
Evolution and Reproductive Biology of Inflorescences in Lithocarpus, Castanopsis, Castanea, and Quercus (Fagaceae)
}

Robert B. Kaul

University of Nebraska-Lincoln

Follow this and additional works at: https://digitalcommons.unl.edu/bioscifacpub

Part of the Biology Commons, and the Botany Commons

Kaul, Robert B., "Evolution and Reproductive Biology of Inflorescences in Lithocarpus, Castanopsis, Castanea, and Quercus (Fagaceae)" (1986). Faculty Publications in the Biological Sciences. 852. https://digitalcommons.unl.edu/bioscifacpub/852

This Article is brought to you for free and open access by the Papers in the Biological Sciences at DigitalCommons@University of Nebraska - Lincoln. It has been accepted for inclusion in Faculty Publications in the Biological Sciences by an authorized administrator of DigitalCommons@University of Nebraska - Lincoln. 


\title{
EVOLUTION AND REPRODUCTIVE BIOLOGY OF INFLORESCENCES IN LITHOCARPUS, CASTANOPSIS, CASTANEA, AND QUERCUS (FAGACEAE) ${ }^{1}$
}

\author{
RoBert B. KAUL ${ }^{2}$
}

\begin{abstract}
Of Lithocarpus, Castanopsis, Castanea, and Quercus only Lithocarpus frequently bears branched spikes suggestive of the primitive condition in the Fagaceae; the other genera sometimes have them in some individuals. Simple and branched spikes can occur on the same tree. Evolution of the simple spike is interpreted as the loss of branching capacity in the branched spikes. The Fagaceae show various transitional stages from perfect, entomophilous to imperfect, anemophilous flowers and from mixedsex to unisexual spikes. Complete separation of staminate from pistillate function into separate spikes and catkins occurs only in Quercus, which is also the only anemophilous member of these four genera. Lithocarpus is the least specialized while Quercus is the most specialized in inflorescence structure of the four genera.
\end{abstract}

Pathways of inflorescence evolution in Castanea, Castanopsis, Lithocarpus, and Quercus have been proposed that identify Lithocarpus and Quercus as possessing the least and most specialized inflorescences, respectively (Kaul \& Abbe, 1984). The specialized inflorescence character states of Quercus are associated with anemophily and the less specialized states in Lithocarpus, Castanea, and Castanopsis relate to their entomophily (Kaul, 1985). Kaul et al. (1986) suggested that the evolution of anemophily in Quercus [and probably also in another fagaceous species, Trigonobalanus daichangensis (Camus) Forman] was an adaptation for successful pollination in seasons of low pollinator activity in seasonal climates, for example, spring in the temperate latitudes. In such latitudes the anemophilous Fagaceae-Quercus and Fagus - flower briefly in the spring whereas the entomophilous Castanea and northerly species of Castanopsis and Lithocarpus flower over a longer period in early summer. Likewise, flowering peaks in entomophilous paleotropical Fagaceae (Castanopsis, Lithocarpus) coincide with maximum insect activity (Kaul et al., 1986; cf. Fogden, 1972). Quercus, which is anemophilous throughout its range, flowers at various times in the tropics but not in the wettest seasons. Further evidence of the functional aspects of these inflorescences is scanty, and therefore definitive answers to questions about the ancestry and subsequent functional evolution of fagaceous inflorescences must be sought through comparative studies of living and fossil taxa.

In these genera the spikes and catkins usually bear numerous sessile, subsessile, or, in a few instances, pedunculate flower clusters that are variously called dichasia, cymules, or partial inflorescences. They are the only structures that presumably terminate in a flower in these four genera; all other structures-branches, rachises, spikes, and catkins-apparently terminate in a vegetative bud that may or may not be capable of further growth.

The dichasia are surely derived by phylogenetic condensation and the ancestral inflorescences were probably thyrse-like or panicle-like. Some modern Fagaceae, most notably some species of Lithocarpus, produce branched spikes that are themselves aggregated into manybranched inflorescences of higher orders, resulting in the most complex floral displays in the family.

The ancestral fagaceous inflorescence was no doubt more complex than any modern inflorescence in the family. Fey and Endress (1983) have advanced credible evidence that the cupule of the fruit is itself a product of condensation of dichasial branching systems. Further, Hjelmqvist (1948) interpreted some staminate flowers as pseudanthia. Kaul and Abbe (1984) suggested evolutionary changes in fagaceous inflorescences that included loss of syllepsis in both vegetative and reproductive shoots and separation of sta-

\footnotetext{
${ }^{1}$ Research supported by National Science Foundation grants DEB-7921641 and DEB-8206937.

${ }^{2}$ School of Biological Sciences, University of Nebraska, Lincoln, Nebraska 68588-0118.
} 
minate from pistillate flowers in the total inflorescence. We also suggested that the catkins of anemophilous Fagaceae were derived from spikes of entomophilous ancestors and that there is a rough gradient of decreasing inflorescence complexity with increasing latitude.

In our previous papers (Kaul \& Abbe, 1984; Kaul, 1985) some complex fagaceous inflorescences were described and illustrated. Here I elaborate upon our work, illustrate additional examples of complex inflorescences, and provide further evidence for their interpretation as the least specialized forms among extant Fagaceae. It must be emphasized that even the least specialized extant forms are advanced for angiosperms as a whole, as evidenced by the presence of such extreme reductions as dichasia and cupules in every species.

\section{MATERIALS}

I have examined thousands of specimens of paleotropical, eastern Asiatic, and North American species of Castanea, Castanopsis, Lithocarpus, and Quercus that were gathered by my colleagues and me with this and related studies in mind. All the specimens illustrated here are in my personal collection but various sets of duplicates are deposited at A, GH, K, L, and US.

Nomenclature herein follows Soepadmo (1972) for the paleotropical species and for generic delimitation.

Figures 4-16 show actual specimens portrayed diagrammatically and are not intended necessarily to be typical of the species. Blackened circles indicate pistillate dichasia and open circles indicate staminate dichasia; quantities of each are only approximated.

\section{TERMinOLOGY}

Figures 1-3 illustrate many of the structures and terms used here. A shoot system (a major indeterminate axis with a leader that periodically undergoes extension growth, and bearing branches) can include proleptic or sylleptic shoots (produced with or without a resting period of the parent bud, respectively) or both, all or nearly all of them floriferous. Most shoots are longshoots (with normally-extended internodes) but some, especially in Quercus, are short-shoots (with reduced internodes). The total inflorescence includes all the floriferous shoots on a shoot system. Spikes are non-pendent and non-foliose; they may be simple spikes without obvious branches or branched spikes that bear one or more floriferous branches. Catkins are the unbranched, pendent, staminate axes of Quercus and Trigonobalanus daichangensis. For simplicity, bract is used here for any non-foliar leaf homologue irrespective of its size or placement.

Except for the dichasia (a term used here generally for the flower clusters, whether or not they are strictly dichasial), all axes terminate in a vegetative bud that is often abortive. Some of these axes are capable of further growth (indeterminate) but some are not (determinate). These genera are pantotonic (cf. Briggs \& Johnson, 1979) in that nearly every leaf- or bract-bearing node is floriferous, although not necessarily synchronously in a flush.

\section{OBSERVATIONS}

\section{PHENOLOGY AND GROWTH HABITS}

The temperate and tropical species of these genera exhibit rhythmic growth, that is, they flush at intervals. More northerly species flush more or less synchronously at a locality at least once a year in spring or early summer; some have succeeding flushes in the same growing season but only the first flush bears flowers and all but the final flush produce branches. Paleotropical species of low and middle elevations often flush and flower repeatedly in a year but there is wide intra- and interspecific variation in local flushing patterns. Sometimes the flushes are so closely spaced that anthesis in one is finishing when the next flowering begins. In some tropical lowland species flushing is non-synchronous even on a single tree (Kaul et al., 1986).

Certain principles apply to the sequence of events in the growth of the trees and some of these are illustrated in Figures 1-3. All species produce flowers on spikes or catkins borne singly or on reproductive shoots and short-shoots in the leaf axils of the current flush and often also in the axils of the previous flush. Most leaves and some bracts subtend one of these structures. In species that branch sylleptically (some species of tropical Castanopsis, Lithocarpus, and Quercus) the indeterminate shoots are also floriferous (Fig. 6 and cf. Kaul \& Abbe, 1984). Fertile proleptic shoots are produced synchronously with the extension growth of the leader in a branch system (Figs. 5, 15, and numerous figures in Kaul \& Abbe, 1984) but sometimes they precede it 

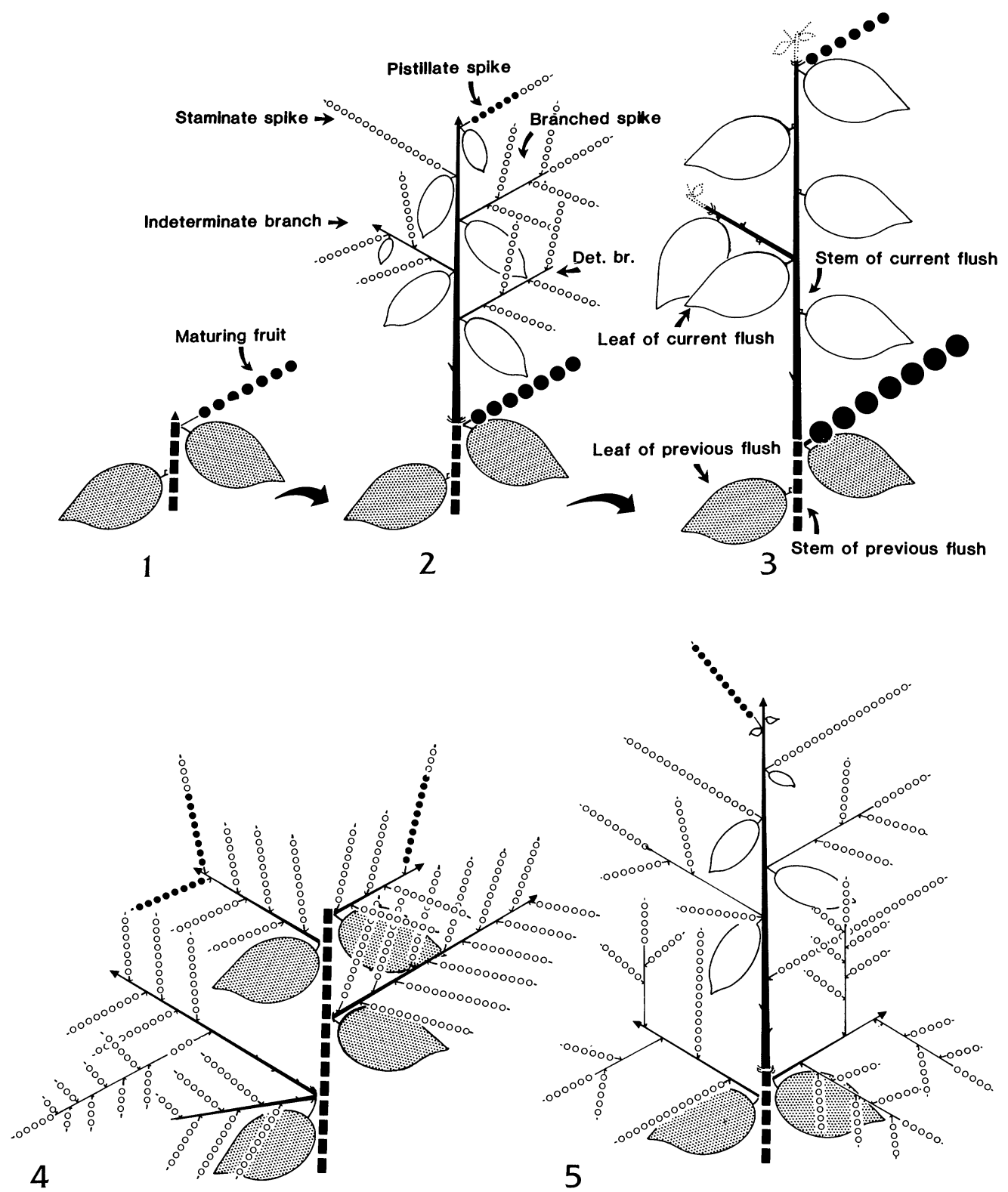

FIGURES 1-5. 1-3. Development of a single flush.-1. Before flush begins. Maturing fruit of previous flush present. Apical bud (triangle) still dormant. -2. End of flush; anthesis. Determinate (without apical bud) and indeterminate (with apical bud) shoots indicated, along with simple and branched spikes. Uppermost spike is androgynous; pistillate dichasia shown in black, staminate as open circles. - 3. Post-anthesis. Staminate spikes have fallen, as has the determinate shoot. Fruits of previous flush nearing maturity but those of current flush are immature. Potential succeeding flush stippled. -4. Lithocarpus elegans (Bl.) Hatus. ex Soep., from Thailand. Most shoots are indeterminate and one bears a branched spike (left center). Apical bud of the main axis abortive.5. L. leptogyne (Korth.) Soep., from Borneo. Branched spikes are borne on the leader and on the shoots. 

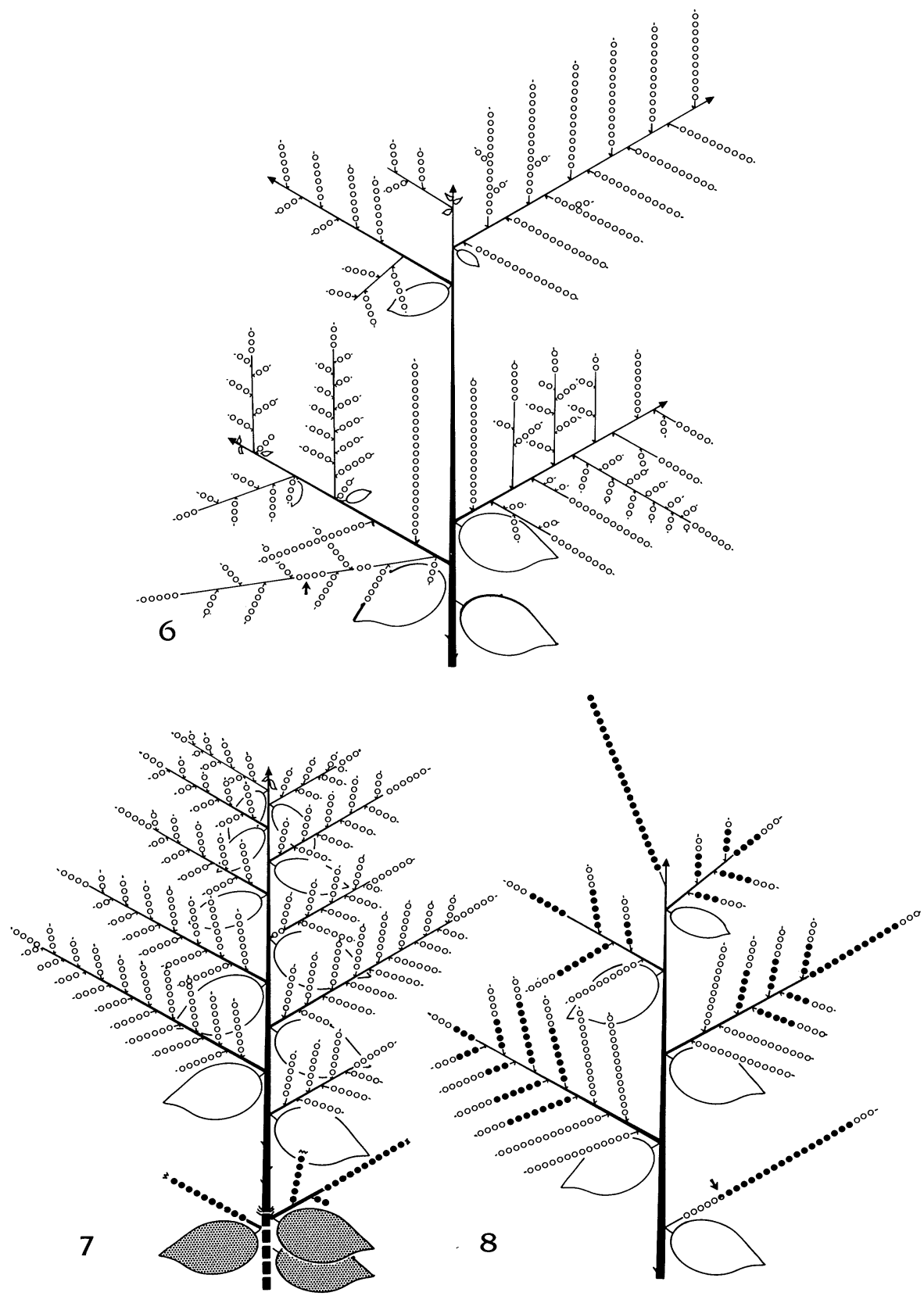

Figures 6-8. Lithocarpus. -6. L. sundaica (Bl.) Rehd., from the Malay peninsula. Maturing flush with numerous branched spikes borne on indeterminate shoots. Pistillate spikes have not yet appeared.-7. L. brevicaudata Hayata, from Taiwan. New flush approaching anthesis. Each new leaf subtends a branched spike. New pistillate spikes have not yet formed, but those of the previous flush carry maturing fruits and were branched.8. L. lampadaria (Gamble) A. Camus, from the Malay peninsula. Four branched spikes each bear many androgynous branches. The simple spike at the lower right is androgynecandrous and bears one dichasium with both staminate and pistillate flowers (arrow). 
(Figs. 4, 16). These proleptic shoots arise from dormant axillary buds at the nodes of the previous flush, whether or not the leaves of that flush are still present.

All determinate axillary reproductive structures, including entire spike- or catkin-bearing shoots, are shed after anthesis except the spikes with pistillate dichasia. Immature fruits of the previous flush are often present at the time of subsequent flushes (Figs. 1-3, 14, 15, 24), a characteristic of tropical species and of some temperate-zone species.

The first nodes beyond the bud scales typically produce only bracts, but these often subtend fertile axes as large as, or even larger than, those axillary to the fully-developed foliage leaves beyond (Figs. 5, 14, 15). Sylleptic shoots usually produce normal foliage at all their nodes.

The floral displays of Lithocarpus, Castanopsis, and Castanea develop with the new flushes at the branch tips and are therefore easily seen from a distance. Added prominence is given by the somewhat colorful developing leaves in the tropical species. The floral displays are often massive, light in color, and distinctly fragrant and thus attract clouds of insects. The displays of Quercus are also often substantial but are drab, odorless, and inconspicuous, especially when hidden among the leaves in evergreen species. In all four genera the pistillate spikes are borne distally in the total inflorescence and are thus exposed.

\section{SPIKES, CATKINS, AND OTHER REPRODUCTIVE BRANCHES}

Many species produce spikes that bear only staminate, only pistillate, or various combinations of staminate and pistillate flowers; Quercus has only staminate catkins and pistillate spikes. Furthermore, some individuals of some species (except Quercus) regularly produce simple spikes whereas others produce more complex structures. For example, only one tree each of Lithocarpus dealbata (Fig. 10), L. elegans (Fig. 4), $L$. harmandii (Fig. 12), and L. lampadaria (Fig. 8) bore branched spikes out of eight, 11, five, and nine trees respectively examined from widely separated areas. Such inconsistency is not confined to inflorescences but is well-known in leaf and even fruit morphology throughout the family. In contrast, most trees of $L$. gracilis, $L$. cooperta (Fig. 9), L. brevicaudata (Figs. 7, 24) and L. leptogyne (Fig. 5) had branched spikes.
It is obvious from inspection of Figures 4-27 that the structure of reproductive axes varies even on a single shoot. It is common for the extensiongrowth axes to produce a variety of axillary shoots that are more complex acropetally (Figs. 10, 12, 13) or basipetally (Figs. 5, 6) or medially (Figs. $7,8,11)$. When proleptic reproductive shoots appear synchronously with a new flush, as they usually do, they too are included in these gradients (Figs. 4, 5).

The leader and some reproductive shoots are indeterminate (e.g., Fig. 2) but their apical buds remain dormant until the next flush, by which time the spikes or catkins have fallen. Other reproductive shoots are determinate and produce only spikes (Fig. 2); these entire shoots are often deciduous after anthesis unless they bear pistillate flowers. Determinate shoots must be distinguished from branched spikes; the latter have staminate flowers on the rachis beyond the most distal branch and lack a distinct apical bud, whereas the former clearly terminate in an abortive bud and lack flowers anywhere on the primary axis. In some instances determinate and indeterminate shoots occur, serially, with simple and branched spikes on a branch and the patterns can vary from branch to branch on a tree. Thus the total inflorescence defies classification beyond panicle, sensu lato.

Lithocarpus. Of the four genera, Lithocarpus shows the greatest variety of inflorescence modifications. Whereas some species regularly produce branched spikes mixed with simple spikes and various reproductive shoots (Figs. 2-12, 23$25,27)$, many, perhaps most, species have simple spikes only, although these may be grouped on shoots that themselves produce massive floral displays (Figs. 25, 27). The patterns approach those of Quercus in some species.

Most of the inflorescence complexity is found in the staminate shoots and spikes but in a few species, for example, L. brevicaudata (Figs. 7, 24) and L. lampadaria (Fig. 8), the pistillate spikes are branched too. Of the species studied, L. lampadaria has the most complex branching of spikes that bear pistillate flowers. In it, large branched spikes bear numerous pistillate dichasia and even more numerous staminate dichasia. Some dichasia include both staminate and pistillate flowers (Fig. 8, arrow) and some spikes have the staminate and pistillate dichasia mixed for short distances (Fig. 20).

The spikes bearing pistillate dichasia in $L$. 

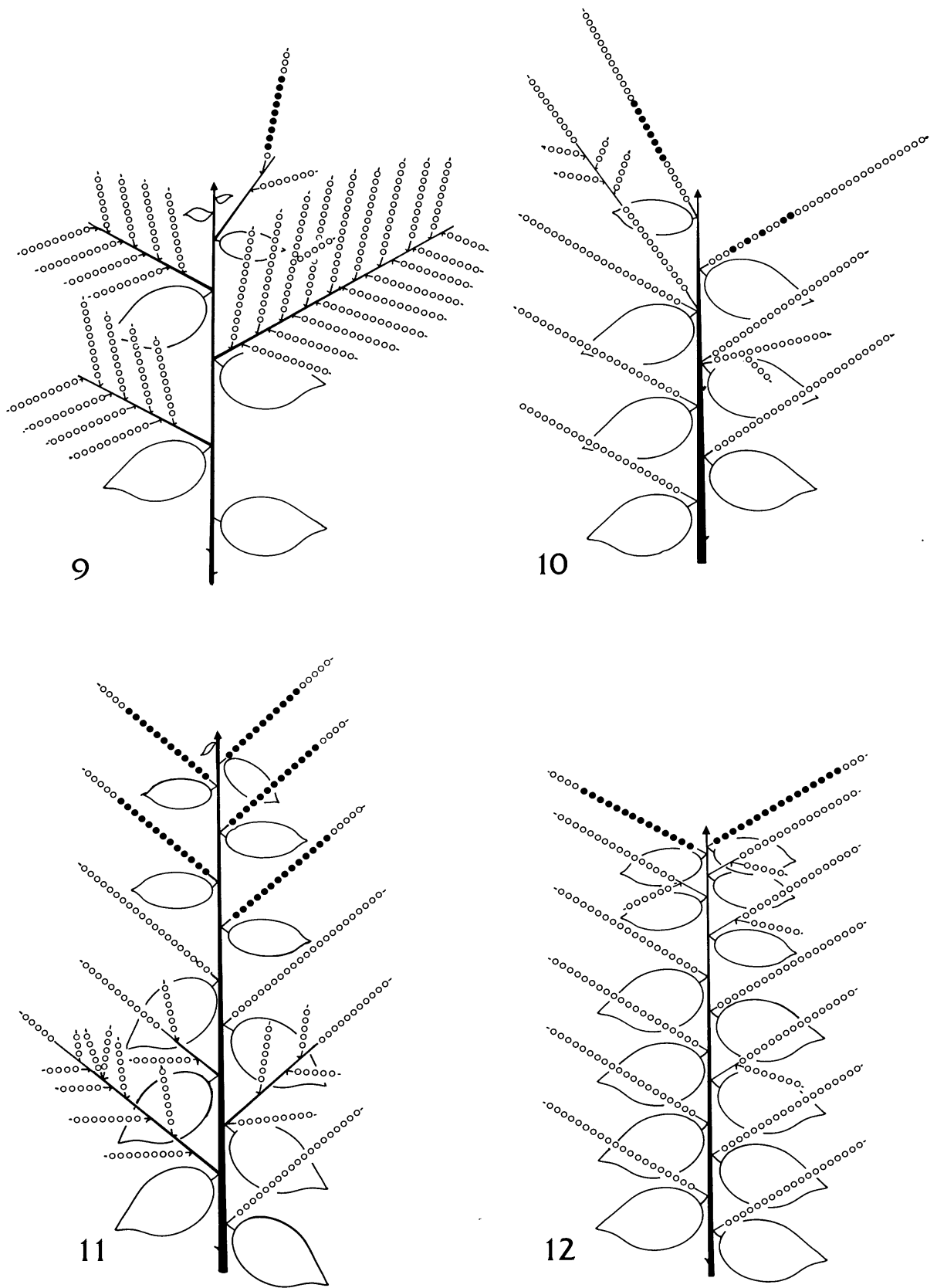

Figures 9-12. Lithocarpus. -9. L. cooperta (Blanco) Rehd., from Borneo. Of the four determinate (without apical buds indicated) shoots, one bears a single branched spike. - 10. L. dealbata (Hook. f. \& Thoms.) Rehd., from Thailand. Most spikes are simple but two are branched. The uppermost spike is androgynecandrous and the penultimate spike has the staminate and pistillate dichasia mixed along the axis. -11 . L. conocarpa (Oudem.) Rehd., from the Malay peninsula. Simple and branched spikes mixed along the axis. Androgynous spikes are distal.-12. L. harmandii A. Camus, from Cambodia. Most spikes are simple but four staminate spikes each bear a single branch. 

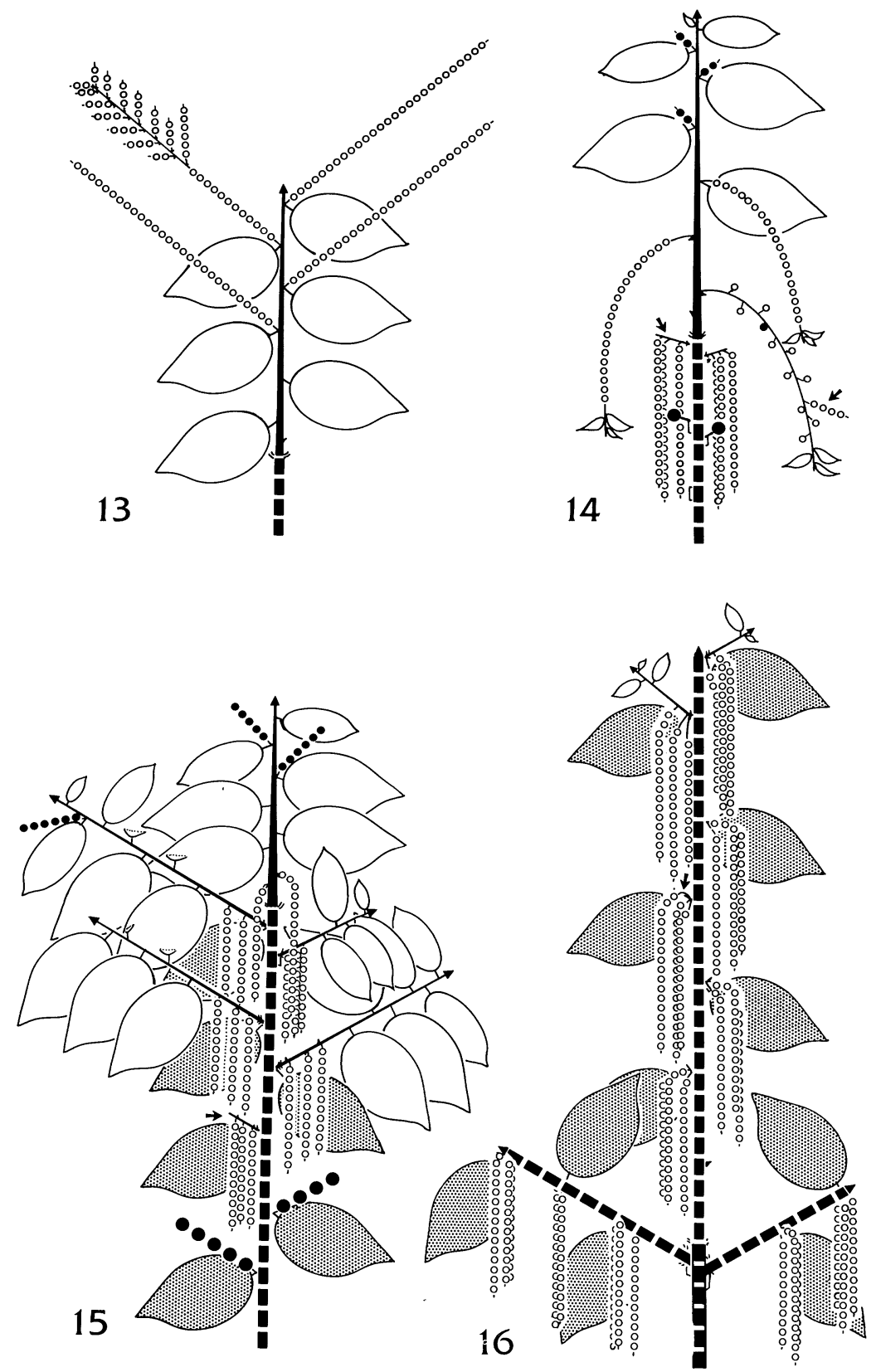

FIGURES 13-16. - 13. Castanea crenata Sieb. \& Zucc., from Taiwan (cultivated). The uppermost dichasia of one spike are replaced by staminate branches. -14 . Quercus marilandica Muenchh., from Nebraska. Branch from a tree that annually bears proliferative catkins and branched catkins (right arrow). Left arrow indicates a staminate short-shoot that emerged from a bud of the previous flush. - 15. Q. pachyloma O. Seem., from Taiwan. Typical inflorescence for many Quercus species. Proleptic indeterminate long-shoots are basally floriferous and the uppermost one, as well as the leader, bears pistillate spikes. One staminate short-shoot (arrow) is shown.16. Q. gilva Blume, from Taiwan. Although the new flush has barely begun to produce extension growth, each leaf of the previous flush has produced a proleptic, staminate short-shoot in its axil. 

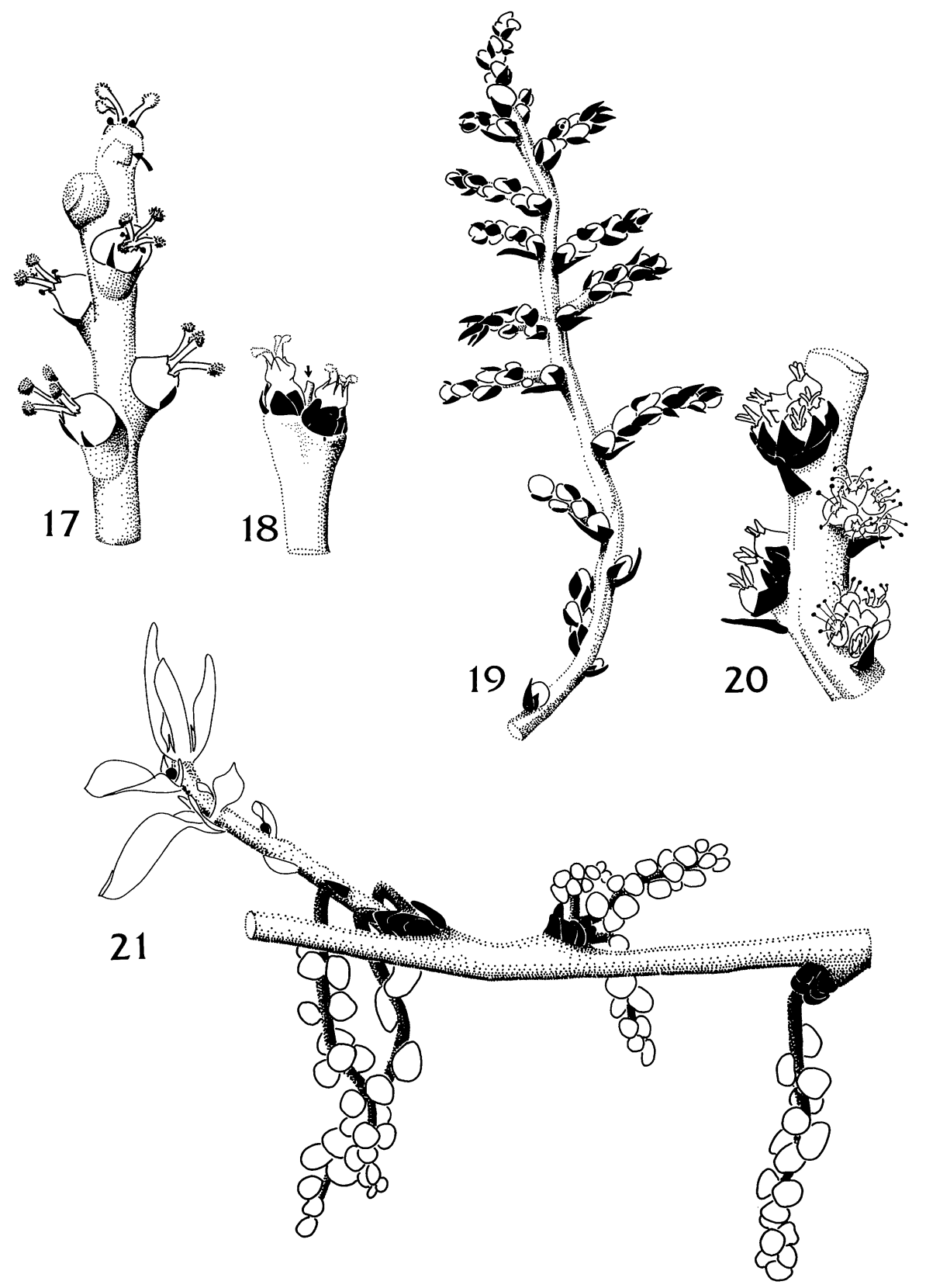

Figures 17-21.-17. Quercus cambodiensis Hick. \& A. Camus, from Cambodia. Pistillate spike in anthesis. Some flowers bear stamens. Abortive vegetative apex indicated by the arrow. -18 . Q. borealis Michx. f., from Nebraska. Pistillate spike with only two one-flowered dichasia. Abortive vegetative apex indicated by the arrow. 19. Lithocarpus brevicaudata branched spike just before anthesis. - 20. L. lampadaria, from the Malay peninsula. Portion of spike showing mixed staminate and pistillate dichasia.-21. Quercus chapmanii, from Florida. Stem segment showing long-shoot (left) and two short-shoots, one of which bears a single catkin. Pistillate spikes are forming in two leaf axils. 

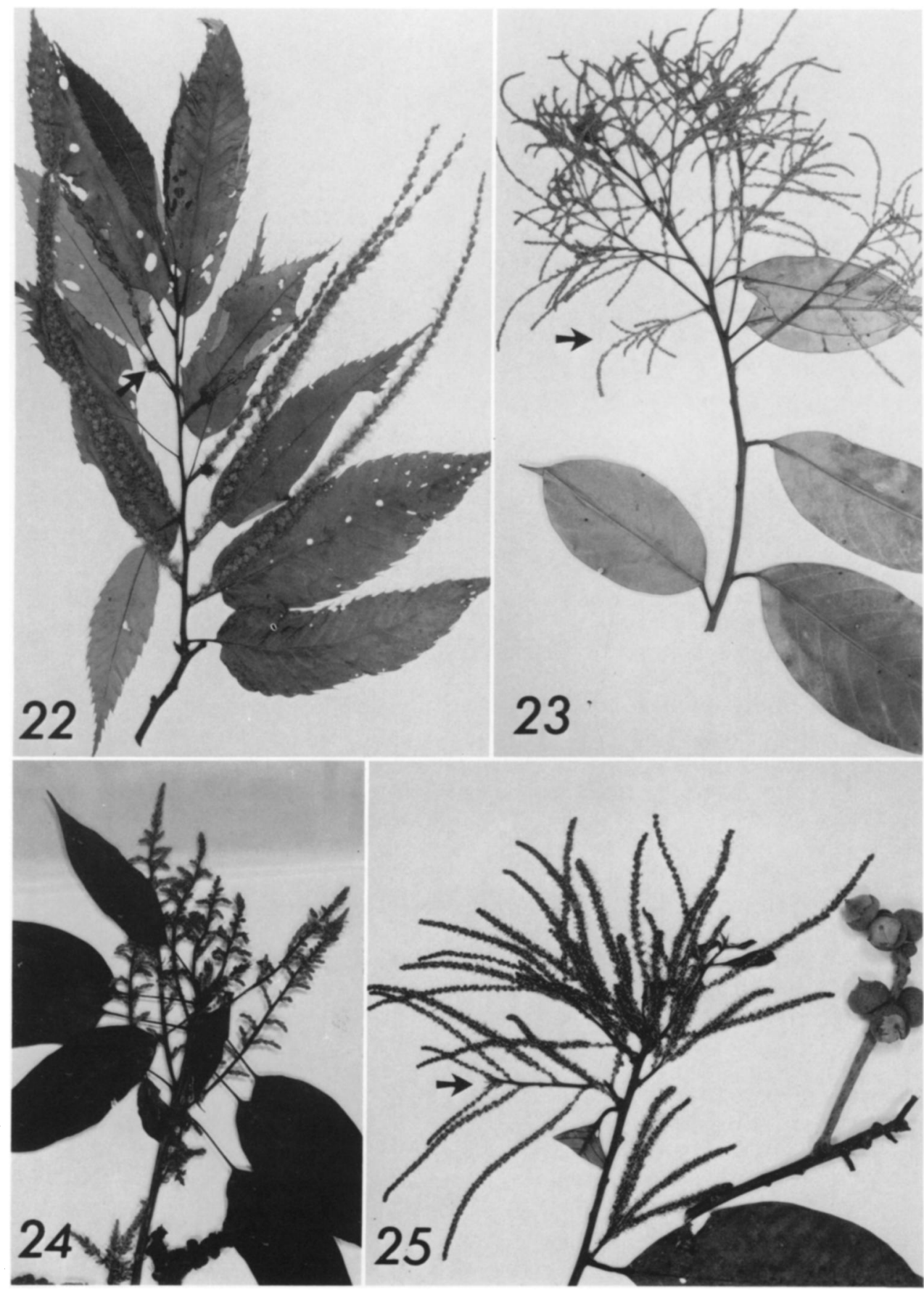

Figures 22-25.-22. Castanea crenata Sieb. \& Zucc. Arrow indicates one of two pistillate dichasia on that spike. Two other spikes have a single basal pistillate dichasium and four spikes are entirely staminate. -23 . Lithocarpus sundaica (Blume) Rehder. Arrow shows a branched spike. No pistillate spikes are visible. Some leaves have fallen.-24. L. brevicaudata Hayata showing prominent branched spikes. -25 . L. neorobinsonii A. Camus. Arrow indicates an indeterminate reproductive branch whose apical bud is barely visible. Below it, on the right side of the stem, is a determinate reproductive branch. Maturing fruits of the previous flush are shown. 
brevicaudata are simpler; only the distal one or two spikes have pistillate flowers and are sometimes branched (Fig. 7). Each branch of the spike is androgynous, as is the case in L. lampadaria. Irrespective of the complexity of branching in these species, the pistillate dichasia are most abundant distally in the total inflorescence.

A variety of branching patterns in the staminate spikes and shoots is shown in Figures 4-7, $9-12,19,23-25$, where there is a seemingly random interchangeability of simple with branched spikes on both the leader and lateral axes. Again the gradient of complexity is neither acropetal nor basipetal in the genus as a whole but apparently varies, even on the individual tree. In some cases illustrated, the branched spikes are more abundant acropetally (Figs. 9, 10, 12) or basipetally (Figs. 6,11 ) but elsewhere they are borne throughout (Fig. 7).

Some spikes are unbranched, some have one branch (Figs. 6, 9, 12), and some have many (Figs. 7, 19, 24). Sometimes staminate dichasia occur directly on the primary axis among or below the branches (Figs. 6, arrow; 19). The branches of the spikes occur at dichasial nodes and are subtended by the same bract pattern as the dichasia (Fig. 19).

The single New World species of Lithocarpus, L. densiflora (H. \& A.) Rehd., regularly exhibits a few branched spikes (Kaul \& Abbe, 1984), suggesting that this long-isolated species has retained this primitive character state.

Castanopsis. There is less variability in inflorescence structure in Castanopsis than in Lithocarpus. Of the 41 species examined, only the single New World representative, $C$. chrysophylla (Dougl.) A. DC., has even an occasional branched spike (Kaul \& Abbe, 1984, fig. 38). All others produce determinate and indeterminate shoots bearing simple spikes (e.g., Fig. 26) in patterns like those of Lithocarpus.

Castanea. Of the five species of Castanea examined (C. crenata, $C$. dentata, $C$. mollissima, C. pumila, and $C$. sativa) only $C$. crenata bears branched spikes (Fig. 13), which are only occasional even in this species. However, a given tree sometimes produces them abundantly. Most spikes are simple and staminate (Fig. 13) but some of the more distal spikes often bear a few proximal pistillate dichasia (Fig. 22, arrow).

Quercus. The pistillate spikes are always simple and borne singly in the axils of the most distal leaves (Fig. 15). They have one to ten or more dichasia (Figs. 15, 17, 18), each reduced to a single functional flower. Generally, the lowland paleotropical species have more pistillate dichasia per spike than do the montane and northern species. Occasionally a few staminate flowers are present on the spike, and often there are perfect flowers (Fig. 17). The vestigial vegetative apex is frequently prominent (Figs. 17, 18, arrows).

The catkins are always staminate (except in distinctly aberrant instances) and are borne on both long- and short-shoots. On the long-shoots they are commonly produced singly in the axils of the lower bracts (Figs. 15, 21), but they sometimes occur in leaf axils as well. Short-shoots appear singly and proleptically at the nodes of the stem of the previous flush (Figs. 14-16, arrows; 21 ). They carry one to ten catkins and are invested at the base with the bracts of the bud that enclosed them (Fig. 21). Most short-shoots abscise soon after anthesis but a few eventually elongate and produce leaves. Figure 21 shows part of a branch that bears short- and long-shoots with catkins; one short-shoot has but a single catkin whereas another has three, as does the long-shoot.

Figure 15 illustrates the typical condition in Quercus. Pistillate spikes are borne in leaf axils of the leader and (often) one or a few of the most distal proleptic branches. Catkins appear on all the long-shoots of the current flush as well as on the short-shoots. Because Figure 15 illustrates an evergreen species, leaves of the previous flush are shown. Most leaves are sterile at the time they appear, except for those that subtend pistillate spikes, but many leaves will subtend axillary long- or short-shoots in the next flush.

Figure 16 illustrates a rather common phenomenon in paleotropical Quercus: the appearance of proleptic, reproductive short-shoots before significant extension growth occurs. The extension growth also bears some catkins and all the pistillate spikes. However, some such protandry (at the inflorescence level) occurs in more northerly species too, insofar as they display at least some catkins in anthesis before the pistillate flowers are receptive.

Branched catkins (equivalent to the branched spikes of the other three genera) are occasional in many species but somewhat common in a few. For example, $Q$. elmeri of Borneo has a few on some trees and $Q$. marilandica of the southeastern United States regularly produces them on an 

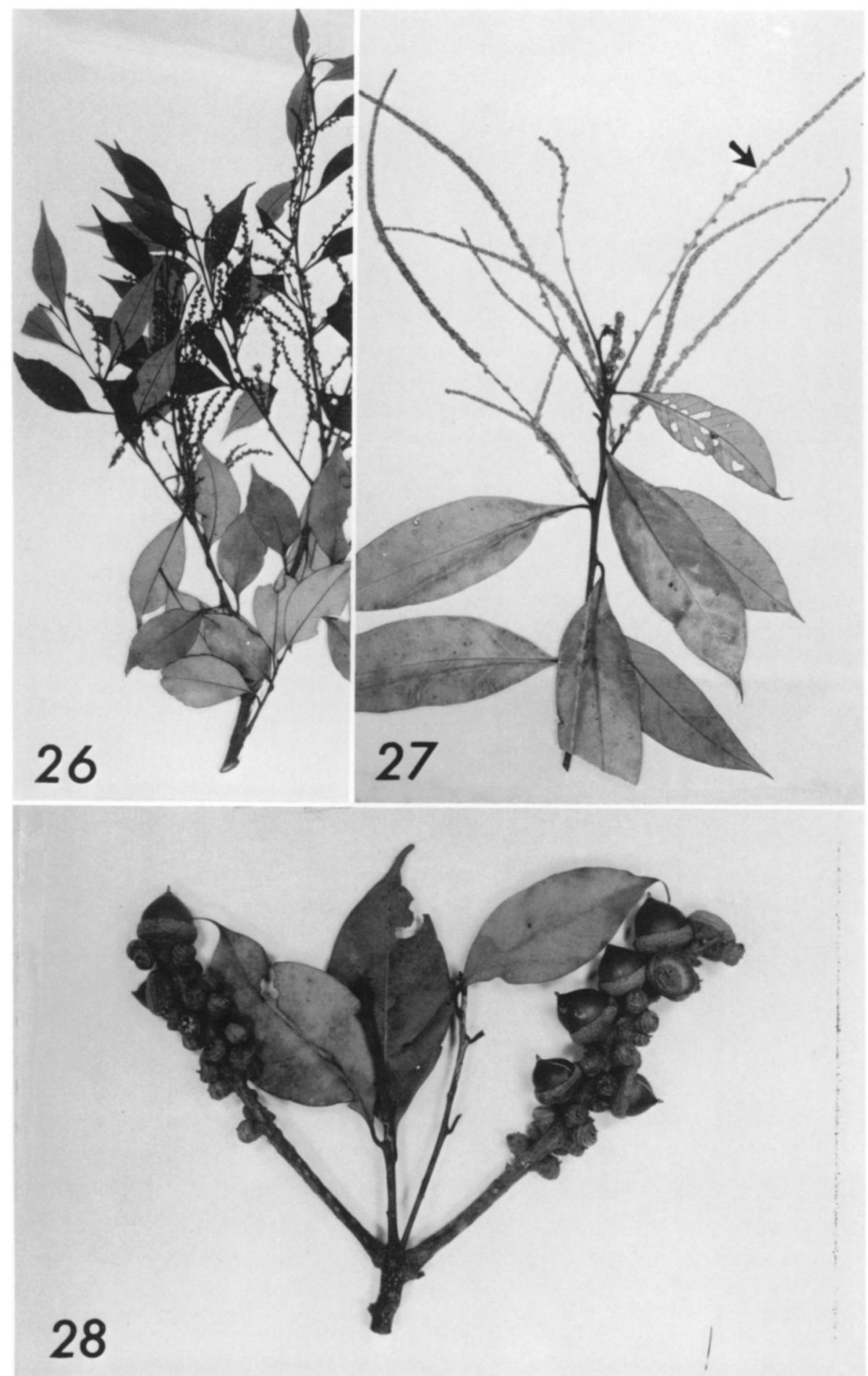

Figures 26-28. -26. Castanopsis cuspidata Schottky. Simple staminate spikes are borne singly in the axils of most new (darker) leaves. - 27. Lithocarpus dealbata (Hook. f. \& Thomson) Rehder showing simple staminate spikes, some of them on indeterminate branches (obscured). The upper two spikes bear some pistillate and 
occasional tree. Figure 14 illustrates a branched catkin in the latter species, from a tree that was observed to produce them regularly for nine years. Most of the catkins are simple, whether or not they are borne on the current flush's long- or short-shoots. Some of the catkins, although unbranched, are somewhat indeterminate in that they proliferate beyond the floriferous region and develop a few small leaves; after anthesis the dichasia drop from these proliferative catkins but the axis and leaves persist. An occasional proliferative catkin is also branched (Fig. 14, right arrow) and sometimes bears one or two pistillate dichasia.

\section{DisCUSSION}

The multiplicity of branching patterns of staminate spikes and shoots, particularly in Lithocarpus, shows that at least in some species flexible and variable patterns are the normal condition. The simple, unisexual spike or catkin is the advanced state in the family and occurs in most species, but a few species have retained branched spikes that suggest more complexity in ancestral forms of the genus. Of the four genera considered here, Lithocarpus has not only the most primitive inflorescences but also, according to Soepadmo (1972), the least specialized dichasia. The other genera, and especially Quercus, have achieved more stability in inflorescence structure and have only occasional inflorescences suggestive of more complex ancestry. Not only does Quercus have complete separation of pistillate from staminate function in most species, but it also bears the determinate reproductive shoots (short-shoots in this case) only proleptically, in contrast with Lithocarpus, in which such shoots occur both sylleptically and proleptically. In Quercus, the spikes bearing pistillate flowers are morphologically very distinct from the catkins and well removed from them. In Lithocarpus, Castanea, and Castanopsis, by contrast, the pistillate flowers usually share a spike with at least a few, and often with very many, staminate flowers. Therefore, I conclude on morphological grounds, by employing the concepts of assessing evolutionary advancement by, among other things, the degree of spatial separation of staminate from pistillate functions, that Quercus is the most advanced of the four genera.

Separation of staminate from pistillate functions has not yet progressed to dioecy in these genera. In fact, many species have morphologically (if not functionally) perfect flowers, including a few Quercus species, and mixed-sex dichasia are frequent in Lithocarpus and Castanopsis (Kaul \& Abbe, 1984). This contrasts with two putatively related families, Betulaceae and Juglandaceae, in which monoecy is clearly established. Those families are entirely anemophilous but only Quercus is, of the four fagaceous genera studied here, and it shows the closest approach to monoecy. This adds to the extensive evidence that monoecy (and also dioecy) is characteristic of anemophilous trees. Thus the Fagaceae can be interpreted as having some transitional stages from perfect, entomophilous flowers to imperfect, anemophilous flowers and from mixed-sex spikes to unisexual spikes.

Homologies of staminate and pistillate spikes are indicated by numerous and frequent transitional forms, especially in Lithocarpus and Castanopsis. The relationships of simple to branched spikes and of the spikes to reproductive shoots are also clarified by the presence of intermediates, even on a single shoot system. Furthermore, every transitional stage between strictly staminate and strictly pistillate dichasia can be found, especially in Lithocarpus, and both of those extremes must be considered ultimate modifications. While the staminate dichasia do not have an obvious cupule like that of the pistillate dichasia, there are suggestions of a cupular homologue in the abundant bracteation that characterizes some of them (Kaul, in prep.).

The branches of the branched spikes occur at the sites of dichasia and, in fact, even have the same basal bracteation as the dichasia. Evolution of the simple spike can be interpreted as loss of branching capacities in the branched spikes. (The opposite change is not impossible: reactivation of meristems in dichasia could produce branched from simple spikes.) Such a loss seems consistent with the losses of flowers and internodal elon-

staminate dichasia, the point of separation between the distal staminate and proximal pistillate dichasia being indicated by the arrow.-28. L. suffruticosa (Ridl.) Soep. with two mature pistillate spikes. Typically, not all pistillate flowers develop fruit. 
gation that occurred during evolution of the individual dichasium. The interchangeability of branches with dichasia suggests that the dichasia (both staminate and pistillate) are the result of evolutionary condensation of branches.

Most of the critical work on the reproductive biology of inflorescences has been done on herbaceous plants [see Wyatt (1982) for a review] but there is no reason to suspect that the principles emerging from those studies would not apply to trees. Such research in the Fagaceae might help to explain such things as miniaturization of flowers and the accompanying evolution of the cupule, the failure of the family to advance to dioecy despite its antiquity, and the instability of inflorescence patterns in some species. Also of interest is the adaptive value of the formation of the pistillate flowers distal to the staminate (so pronounced in the Fagaceae), which is common in both the anemophilous and the entomophilous monoecious dicotyledons (but not in the monocotyledons, where the opposite condition prevails). Furthermore, such studies could help to explain the factors involved in the change from entomophily to anemophily in the Fagaceae, a topic reviewed for plants in general by Regal (1982) and Whitehead (1983) and broached for the Fagaceae by Kaul et al. (1986) but in need of substantially more research.

\section{Literature Cited}

BrigGs, B. G. \& L. A. S. Johnson. 1979. Evolution in the Myrtaceae-evidence from inflorescence structure. Proc. Linn. Soc. New South Wales 102: 157-256.

FEY, B. S. \& P. K. ENDRESS. 1983. Development and morphological interpretation of the cupule in Fagaceae. Flora 173: 451-468.

Fogden, M. P. L. 1972. The seasonality and population dynamics of equatorial forest birds in Sarawak. Ibis 114: 307-343.

HJelmQvist, H. 1948. Studies on the floral morphology and phylogeny of the Amentiferae. Bot. Not. Suppl. 2: 1-171.

KaUl, R. B. 1985. The reproductive morphology of Quercus (Fagaceae). Amer. J. Bot. 72: 1962-1977. \& E. C. ABBE. 1984. Inflorescence architecture and evolution in the Fagaceae. J. Arnold Arbor. 65: 375-401.

$\longrightarrow$ \& L. B. AвBE. 1986. Reproductive phenology of the oak family (Fagaceae) in the lowland rain forests of Borneo. Biotropica 18 (in press).

Regal, P. J. 1982. Pollination by wind and animals: ecology of geographic patterns. Annual Rev. Ecol. Syst. 13: 497-524.

Soepadmo, E. 1972. Fagaceae. Fl. Males. I, 7: 265403.

Whitehead, D. R. 1983. Wind pollination: some ecological and evolutionary perspectives. Pp. 97108 in L. Real, Pollination Biology. Academic Press, Orlando.

WYATT, R. 1982. Inflorescence structure: how flower number, arrangement, and phenology affect pollination and fruit-set. Amer. J. Bot. 69: 585-594. 